\title{
O TERMO DE AJUSTAMENTO DE CONDUTA COMO FORMA ALTERNATIVA A JURISDICIONALIZAÇÃO NA SOLUÇÃO DOS CONFLITOS AMBIENTAIS
}

\section{THE CONDUCT OF ADJUSTMENT TERM AS FORM ALTERNATIVE TO JURISDICTIONALIZATION THE SOLUTION OF CONFLICT ENVIRONMENTAL}

${ }^{1}$ Tatiana Fernandes Dias Da Silva

\section{RESUMO}

O presente trabalho pretende demonstrar que o Termo de Ajustamento de Conduta (TAC) pode ser uma forma alternativa eficaz frente à jurisdicionalização dos conflitos ambientais. Para tanto se estudou a legislação pátria, a doutrina nacional e estrangeira, jurisprudências e periódicos. O objetivo é comprovar que diante da morosidade da prestação jurisdicional, principalmente nos casos das demandas ambientais, o TAC, como forma extrajudicial de solução de conflitos, poderia ser um remédio eficiente em prol da preservação e proteção do meio ambiente, caso o mesmo fosse mais utilizado pelos órgãos ambientais legitimados e efetivamente fiscalizado o seu cumprimento pelo poder público local.

Palavras-chave: Termo de ajustamento de conduta, Meio ambiente, Jurisdicionalização, Alternativas

\begin{abstract}
This paper aims to demonstrate that the Conduct Adjustment Term (TAC) can be an effective way to forward alternative jurisdictionalization environmental conflicts. Therefore we studied the Brazilian legislation, the national and foreign doctrine, case law and journals. The goal is to prove that given the slow pace of judicial assistance, especially in cases of environmental demands, the TAC, as extrajudicial form of dispute resolution, could be an effective solution for the preservation and protection of the environment if it were more used by legitimate environmental agencies and effectively monitored compliance by the local government.
\end{abstract}

Keywords: Conduct adjustment term, Environment, Jurisdictionalization, Alternatives

1 Doutoranda em Sociologia e Direito pela Universidade Federal Fluminense. Professora em Direito da Universidade Estácio de Sá. Universidade Estácio de Sá - UNESA, São Paulo. Brasil

E-mail: tfdsilva@gmail.com 


\section{INTRODUÇÃO}

A preocupação mundial com a proteção e preservação do meio ambiente teve início no século XX, apesar de a degradação ambiental ser pretérita a esta data. Desde a Revolução Industrial, ocorrida no século XVIII, o modo como o homem utiliza os recursos naturais no processo de desenvolvimento econômico tem provocado à deterioração das condições ambientais.

A primeira conferência da Organização das Nações Unidas (ONU) sobre o tema ocorreu em 1972, na cidade de Estocolmo, capital da Suécia, denominada Conferência das Nações Unidas sobre o Meio Ambiente Humano. Neste encontro, onde estavam presentes nas discussões mais de 400 instituições governamentais e não governamentais, contou com a participação de 113 países e teve como objetivo precípuo adotar critérios e princípios que oferecessem aos povos do mundo inspiração e guia para preservar e melhorar o meio ambiente humano. Nele ficou cristalino que "o homem é ao mesmo tempo obra e construtor do meio ambiente que o cerca, o qual the dá sustento material e lhe oferece oportunidade para desenvolver-se intelectual, moral, social e espiritualmente", que a proteção do meio ambiente humano é fundamental por afetar o bem-estar dos povos e o desenvolvimento econômico do mundo, que, nos países industrializados, os problemas ambientais estão em grande parte relacionados com a industrialização e o desenvolvimento tecnológico e que todos nós devemos aceitar a responsabilidade sobre o meio ambiente num esforço comum em protegê-lo e preservá-lo.

A conferência permitiu que em dezembro de 1972, a Assembleia Geral da ONU criasse o Programa das Nações Unidas para o Meio Ambiente (PNUMA), que passaria a coordenar os trabalhos daquela em nome do meio ambiente global. Em 1983, o Secretário- Geral da ONU convidou Gro Harlem Brundtland, ex-primeira Ministra da Noruega, para estabelecer e presidir a Comissão Mundial sobre o Meio Ambiente e Desenvolvimento. Quatro anos após, em abril de 1987, estava pronto o Relatório Brundtland (Nosso Futuro Comum) que popularizou a expressão desenvolvimento sustentável, apresentando um novo olhar sobre o desenvolvimento, definindo-o como sendo "o desenvolvimento que encontra as necessidades atuais sem comprometer a habilidade das futuras gerações de atender suas próprias necessidades". 
Vinte anos após a primeira conferência da ONU sobre meio ambiente, em 1992, na cidade do Rio de Janeiro, houve a Conferência das Nações Unidas sobre Meio Ambiente e Desenvolvimento (CNUMAD), conhecida popularmente como Rio-92 ou Cúpula da Terra. Neste segundo encontro, os países signatários reafirmaram a Declaração assinada em Estocolmo, em 16 de junho de 1972, buscaram estabelecer uma parceria global de cooperação entre os Estados, os setores-chaves da sociedade e os indivíduos, com o fim de proteger a integridade do sistema global de meio ambiente e desenvolvimento. Nesta reunião foram estabelecidos 27 princípios, assumindo a preocupação com o desenvolvimento sustentável e ratificando que o homem tem direito a uma vida saudável, produtiva e em harmonia com a natureza.

Esses ideais também fizeram parte da Conferência Rio+20, realizada pela ONU, no município do Rio de Janeiro, em 2012, que assim ficou conhecida pois marcou os vinte anos de realização da Conferência das Nações Unidas sobre Meio Ambiente e Desenvolvimento (Rio92) e contribuiu para definir a agenda do desenvolvimento sustentável para as próximas décadas. Esse encontro teve como temas centrais a economia verde no contexto do desenvolvimento sustentável, a erradicação da pobreza e a estrutura institucional para o desenvolvimento sustentável.

No Brasil, somente em 1981, dez anos após a Conferência de Estocolmo, foi editada a Política Nacional do Meio Ambiente (PNMA), Lei 6.938/81, que teve por objetivo a preservação, recuperação da qualidade ambiental propícia à vida, visando assegurar condições para o desenvolvimento socioeconômico, aos interesses da segurança nacional e à proteção da dignidade da vida humana. A norma disciplinou princípios, diretrizes, objetivos específicos, instrumentos, criou o Sistema Nacional do Meio Ambiente (SISNAMA) e o Conselho Nacional do Meio Ambiente (CONAMA), tudo em prol da proteção e preservação ambiental.

A Constituição da República Federativa do Brasil (CRFB), promulgada em 1988, trouxe o meio ambiente ao patamar constitucional criando capítulo próprio para o mesmo, artigo 225. Perante a lei constitucional, todos têm direito ao meio ambiente ecologicamente equilibrado, que é um bem de uso comum do povo e essencial à sadia qualidade de vida, devendo o Poder Público e à coletividade defendê-lo e preservá-lo para as presentes e futuras gerações. 
Hoje, abril de 2016, o Brasil possui inúmeras normas jurídicas que visam à proteção e preservação do meio ambiente, sejam elas leis, decretos ou resoluções editadas pelo Poder Público no âmbito municipal, estadual e federal. Contudo, o anseio do ser humano em enriquecer, produzir e consumir, além dos anseios naturais, fez com que essas normas fossem deixadas à margem perante o modelo econômico capitalista. Apesar do texto constitucional prevê a proteção do meio ambiente dentro do capítulo da ordem econômica, artigo 170, inciso VI, da CRFB, o conflito ambiental normalmente surge quando o princípio constitucional do desenvolvimento sustentável se monstra ineficaz frente à economia capitalista de industrialização e consumismo, desrespeitando a preservação ambiental, aclamada no artigo 225 , caput, e afetando diretamente a saudável qualidade de vida, artigo $1^{\circ}$, inciso III, todos da Carta Magna.

\section{DA PRESTAÇÃO JURISDICIONAL E OS MEIOS ADEQUADOS DE SOLUÇÃO DE CONFLITOS.}

As demandas judiciais por serem em sua maioria longas e morosas vêm se tornando um obstáculo a efetiva prestação jurisdicional. Há um processo de perda gradativa da confiança dos cidadãos na capacidade do Estado em assegurar uma prestação jurisdicional rápida e efetiva.

Em 30 de dezembro de 2004, a Emenda Constitucional n. 45 adicionou ao artigo $5^{\circ}$ da Constituição da República Federativa do Brasil, que trata dos Direitos e Garantias Fundamentais, o inciso LXXVIII, que estabelece que "a todos, no âmbito judicial e administrativo, são assegurados a razoável duração do processo e os meios que garantam a celeridade de sua tramitação". Nesta mesma direção foi sancionada a Lei n. 13.105, de 16 de março de 2015, que estabeleceu o Novo Código de Processo Civil Brasileiro, que já se encontra em vigor. A norma em seu artigo, $4^{\varrho}$ deixa claro que "as partes têm o direito de obter em prazo razoável a solução integral do mérito, incluída a atividade satisfativa”.

A morosidade na prestação jurisdicional somados aos princípios constitucionais da razoável duração do processo e da celeridade processual tem conduzido no país a uma permanente reflexão sobre os meios adequados de solução de controvérsias, que hoje, de acordo com a nova Lei de Ritos, são estimulados por juízes e demais operadores do Direito. 
Consagra a norma, em seu artigo $3^{\circ}, \S 3^{\circ}$ que: “A conciliação, a mediação e outros métodos de solução consensual de conflitos deverão ser estimulados por juízes, advogados, defensores públicos e membros do Ministério Público, inclusive no curso do processo judicial". O texto legal também prevê capítulo próprio, na parte especial, livro I, título I, para a mediação e a conciliação no âmbito das ações judiciais.

Como ressalva Humberto Theodoro Junior e outros (2015), a nova lei processual apresenta uma "notória tendência de estruturar um modelo multiportas que adota a solução jurisdicional tradicional agregada à absorção dos meios alternativos." O objetivo seria "uma solução integrada dos litígios como corolário da garantia constitucional do livre acesso do inc. XXXV do art. 5 da CR/1988”. Para o doutrinador essa mescla de técnicas de solução de conflitos se faz necessária perante a hiperjudicionalização desses, pois no Brasil até o que se poderia ser resolvido pela autocomposição, como é feito em outros países, utiliza-se a via judicial.

Humberto Dalla (2015) destaca que, "no Brasil, a partir dos anos 90 do século passado, começou a haver um interesse pelo instituto da mediação, sobretudo por influência da legislação argentina editada em 1995." Nacionalmente, a primeira iniciativa legislativa foi o Projeto de Lei 4.827/98, fruto da proposta da então deputada Zulaiê Cobra. Em 2002, o projeto foi aprovado pela Comissão de Constituição e Justiça da Câmara dos Deputados e enviado ao Senado Federal, que ficou prejudicado diante do substitutivo (Emenda n. 1 CCJ).

Em 2010, foi aprovada, pelo Conselho Nacional de Justiça, a Resolução $n^{\circ} 125$, de 29 de novembro, que dispõe sobre a Política Judiciária Nacional de tratamento adequado dos conflitos de interesses no âmbito do Poder Judiciário. A norma deixa claro em seu artigo $1^{\circ}$ que a Política Judiciária Nacional de tratamento dos conflitos de interesses, tem por objetivo assegurar a todos o direito à solução dos conflitos por meios adequados à sua natureza e peculiaridade.

Somente em, 26 de junho de 2015, foi sancionada a Lei n. 13.140, que disciplina sobre a mediação entre particulares como meio de solução de controvérsias e sobre a autocomposição de conflitos no âmbito da administração pública.

Destaca Humberto Theodoro Junior e outros (2015), que as chamadas técnicas alternativas de resolução de conflitos, como a mediação, conciliação, negociação e arbitragem, é uma tendência mundial, que vem crescendo desde a década de 70 , com o que se 
denominava de Alternative Dispute Resolution (ADRs), como uma opção ao sistema jurisdicional tradicional. Continua os doutrinadores esclarecendo que essa técnica surgiu como forma de aliviar o maquinário oficial da justiça civil, que é incapaz, quantitativamente, de atender a crescente demanda judicial. O fim era o de resolver conflitos de menor complexidade, que não necessitassem de grande conhecimento jurídico e que poderiam ser resolvidos fora da jurisdição.

Dentro do processo de utilização dos meios alternativos para a solução das controvérsias ambientais, alguns países estrangeiros chamam atenção, dentre eles, o Estados Unidos da América (EUA) que, desde os anos 70 do século passado, utiliza métodos extrajudiciais para solucionar os conflitos ambientais locais, que são verdadeiras disputas sociais com o debate entre empresários, industriais, o próprio governo (como empreendedor), as organizações de base comunitária, os movimentos ecológicos e as agências governamentais de regulação. O objetivo é tentar solucionar os danos ambientais gerados pelo avanço do desenvolvimento econômico, fruto de uma economia capitalista predatória e com o uso indiscriminado dos recursos naturais (BREDARIOL, 2001).

Bredariol ainda acrescenta que nos Estados Unidos, em 1980, o campo da resolução alternativa de disputas atingiu o status de busca de soluções conjuntas, se transformando em lei, em 1996 através do Ato de Resolução Administrativa (P.L. 101-552) e do Ato de Regulamentação Negociada (PL 101-648). Foi desta mesma década que algumas empresas e a Agência de Proteção Ambiental dos Estados Unidos (EPA) negociaram com algumas universidades americanas o desenvolvimento de mecanismos e metodologias para a resolução alternativa de disputas (ADR). Cada universidade elaborou a sua própria metodologia e definiu suas próprias estratégias para lidar com os conflitos ambientais. A forma de conciliação se baseou na construção de consenso, na mediação, ou até mesmo no diálogo político.

Na prática o que se vê é que os Estados Unidos possuem uma estrutura bem dimensionada para a resolução dos conflitos ambientais. Instituições como a University of Michigan's Ecosystem Management Initiative, International, a CommunitybasedCollaboratives Research Consortium, o The Willian and Flora Hewlett Foundation, a Sustainable Development Department (SD) e a Food and Agriculture Organization of United Nations (FAO), promovem fora do âmbito judicial a pacificação das controvérsias ambientais. Em 1998, Congresso Nacional Americano, criou o U.S. Institute for Environmental Conflict 
Resolution, esse órgão tem como objetivo, através da imparcialidade, não pardidária, a resolução de disputas ambientais por meio da mediação.

Hoje, início do século XXI, o que prevalece nos EUA é a construção de consenso, que se define como sendo, "aquele em que todos têm interesse em alcançar acordos sobre ações e resultados, para resolver e fazer avançar os assuntos relacionados com a sustentabilidade ambiental, social e econômica",. Essa forma extrajudicial de conflito se transformou para os americanos como uma verdadeira ideologia de negociação de conflitos ambientais.

Atualmente cresce, entre os países desenvolvidos, o uso da Teoria da Decisão para a solução de conflitos ambientais. Essa teoria foi proposta por Backow e Wheeler, e também por Fisher, Ury e Patton (BREDARIOL, 2001) que viabilizaram um método de grandeza multidimensional, para exame, diagnóstico e gerenciamento de conflitos onde as preferências dos atores sociais, critérios e pesos eram combinados para julgar as possibilidades de estratégias de compromis sos entre partes conflitantes.

\section{O TERMO DE AJUSTAMENTO DE CONDUTA}

Os métodos alternativos de solução de conflitos tornaram-se uma opção para efetivar a solução da lide com a participação ativa de todas as partes envolvidas, seja através da conciliação, da mediação, da negociação, da arbitragem ou, como nos casos do meio ambiente, por sua característica, difusa, transindividual, coletiva e indisponível, o Termo de Ajustamento de Conduta (TAC).

O Termo de Ajustamento de Conduta teve a sua origem na legislação dos Estadosmembros, em 1976, com o advento da Lei 6.385, que dispõe sobre o mercado de valores imobiliários. Nesta época, a terminologia adotada era Termo de Compromisso (TC), tratando-

\footnotetext{
${ }^{1}$ Mesa Redonda do Canadá. 1993.
} 
se de um negócio jurídico bilateral, servindo de instrumento da Administração Pública para reafirmar o dever de observância as normas jurídicas vigentes.

Em 1981, a Política Nacional do Meio Ambiente (PNMA), Lei 6.938, fez previsão ao TAC, também com a denominação Termo de Compromisso (TC), nos casos específicos de danos causados ao meio ambiente.

Posteriormente, em 1990, com a edição do Estatuto da Criança e do Adolescente, Lei Federal n. ${ }^{\circ} 8.069$, de 13 de julho, o TAC se fez presente no artigo 211, que determina que "os órgãos públicos legitimados poderão tomar dos interessados compromisso de ajustamento de sua conduta às exigências legais, o qual terá eficácia de título executivo extrajudicial”, e, posteriormente, no mesmo ano, em 11 de setembro de 1990, sancionado o Código de Defesa do Consumidor (CDC), Lei n. 8.078, que, em seu artigo 113, ampliou o acesso a essa forma transacional de solução de controvérsias para os demais interesses difusos e coletivos, em especial o ambiental, vindo a alterar a redação do artigo $5^{\circ}$ da lei da Ação Civil Pública (ACP), Lei n. 7.347, de 24 de julho de 1985, com a inclusão dos $\S 4^{\circ}, \S 5^{\circ}$ e $\S 6^{\circ}$, possibilitando, principalmente com a inclusão do novo $\S 6^{\circ}$, uma resolução alternativa mais célere para os conflitos ambientais e facilitando a sua execução através do Poder Judiciário.

Dispõe a Lei n. 7.347/85, em seu artigo $5^{\circ}, \S 6^{\circ}$, que: “Os órgãos públicos legitimados poderão tomar dos interessados compromisso de ajustamento de sua conduta às exigências legais, mediante cominações, que terá eficácia de título executivo extrajudicial”.

O Estado do Rio de Janeiro, em 14 de setembro de 2000, sancionou a Lei Estadual n. 3.467, que, em seu artigo 101, dispõe sobre as sanções administrativas derivadas de condutas lesivas ao meio ambiente do Estado, ou seja, veio a ratificar o Termo de Ajustamento de Conduta, como mecanismo de pacificação de conflitos ambientais, já sancionado na esfera Federal, através da Lei da Ação Civil Pública (Lei n. 7.347/85), mencionada acima.

A norma estadual deixa claro, em seu artigo, que caberá "para fazer cessar a degradação ambiental", a "celebração de termo de compromisso ou de ajuste ambiental", sendo de "exclusivo critério do Secretário de Estado de Meio Ambiente e Desenvolvimento Sustentáve 1". Legitima assim, a desjudicionalização dos conflitos ambientais. 
O TAC ocupa um lugar de destaque na pacificação de conflitos, onde aquele que causou o dano se compromete a adequar-se a lei ou em reparar a lesão junto a aquele que o sofreu, sob o manto mediador dos órgãos públicos legitimados nos incisos do artigo $5^{\circ}$, e seus incisos, da Lei da Ação Civil Pública, em que também se enquadram o Ministério Público, a Defensoria Pública e, ainda, entidades que compõem a administração direta, indireta ou fundacional desde que desenvolvam atividades de interesse público, e após a celebração do Termo de Ajustamento de Conduta exista a ratificação do Ministério Público, Milaré (2013).

Como escreve Jerônimo Jesus dos Santos (2007), o TAC é "um instrumento que se traduz numa declaração de vontade exarada no processo, num procedimento ou, muitas vezes, é o próprio procedimento seguindo determinada forma ou maneira, contendo determinado e relevante teor", uma vez que o ajustamento deve harmonizar um novo comportamento e a conduta é o principal propósito a ser buscado no termo a ser modificado. Para o autor o TAC pressupõe uma verdadeira mudança de mentalidade em prol da conciliação dos conflitos metaindividuais, não podendo implicar, hora nenhuma, em disposição de tal direito. É uma garantia de pacificação e estabilidade social, que possui nuances na class actions do direito norte-americano.

Sobre as class actions do direito norte-americano, Scarpinella Bueno (2015), destaca que é:

o procedimento em que uma pessoa, considerada individualmente, ou um pequeno grupo de pessoas, enquanto tal, passa a representar um grupo maior ou classe de pessoas, desde que compartilhem, entre si, um interesse comum. Seu cabimento restringe-se àquelas hipóteses em que a união de todos que poderiam ser partes em um mesmo processo (que se afirmam titulares da lide levada ao Estado juiz, portanto) não é plausível (até porque seu número poderia chegar a milhões) ou porque sua reunião, em um só processo, daria ensejo a dificuldades insuperáveis quanto à jurisdição e à competência. (As Class Actions Norte-Americanas e as ações Coletivas Brasileiras: Pontos para uma reflexão conjunta.)

Continua o autor, esclarecendo que as características principais da class actions são: "A classe tem de ser extensa o suficiente de modo a impossibilitar, ou, ao menos, não ser conveniente, a reunião de todos seus membros individualmente considerados em um só processo". E ainda, as questões a serem postas perante o Tribunal têm que ser comuns, isto é, "deverão ser questões de direito ou de fato comuns para toda a classe. O autor (ou os autores) das class actions tem que demonstrar que é representante típico da classe". 
Édis Milaré, em sua obra, Direito do Ambiente (2013), num primeiro momento faz uma crítica ao TAC, afirmando que "a marca da indisponibilidade dos interesses e direitos transindividuais impede, em princípio, a transação, tendo em vista que o objetivo desta alcança apenas "direitos patrimoniais de caráter privado", suscetíveis de circulabilidade". Mas, o autor, logo no parágrafo posterior, afirma que "de situações concretas de dano iminente ou consumado, em que o responsável acede em adequar-se à lei ou em reparar a lesão, seria fechar os olhos a realidade e as exigências da vida recusar pura e simplesmente tal procedimento [...]".

Como narra Rogrigo Nunes Viégas (2007), "para que se estabeleça um quadro de negociação, de resolução de conflitos ambientais, necessita-se que haja, para além de metodologias bem definidas e aplicadas, uma instituição neutra e que tenha infraestrutura." $\mathrm{Na}$ teoria, o objetivo do Termo de Ajustamento de Conduta é a celeridade e eficácia na solução de conflitos, possuindo, segundo Milaré, natureza jurídica de transação, "já que preordenado à adoção de medidas acauteladoras do direito ameaçado ou violado, destinadas a prevenir litígio ou a por-the fim [...]". O doutrinador ainda destaca como requisitos de validade para a celebração do TAC a sujeição à integral reparação do dano, a previsibilidade de cominações para o caso de descumprimento da obrigação, compromisso de ajustamento de conduta parcial, reexame do compromisso pelo órgão superior de revisão e início de sua eficácia, o compromisso de ajustamento de conduta e a responsabilidade pela danosidade ambiental e, como já mencionado, a cima, que o tomador do mesmo seja ente público com legitimidade a propor a Ação Civil Pública.

Roberta Nogueira (2007) salienta que, “o TAC é um tipo peculiar de transação, que tem como finalidade a prevenção do litígio ou o seu próprio fim, devendo abarcar a totalidade das medidas necessárias à reparação do bem lesado (reparação), ou", continua a escrever, "o afastamento do risco ao bem jurídico de natureza difusa ou coletiva (prevenção).” Ainda destaca que, "um grande problema encontrado em relação aos TACs refere-se à fiscalização dos mesmos". Continua, a sua análise ao afirmar que "não há, portanto, uma estrutura eficiente de acompanhamento do cumprimento desses TACs que não seja o próprio denuncis mo das entidades civis e dos indivíduos isolados", pois são esses que geralmente são afetados de forma direta ou indireta pelo descumprimento do compromisso celebrado. 
Merece destaque os TACs que são celebrados com a própria administração pública, na maioria esses não são cumpridos pelo Poder Público, que muitas vezes não executa o que foi pactuado no compromisso nem através de procedimento administrativo nem pela via judicial, cabendo, como já sinalizou o Superior Tribunal de Justiça, astreintes, multa diária, para cumprimento da obrigação (Recurso Especial no $1.540 .360-$ RS, Recurso Especial $n^{\circ}$ 555.542 - AC, Recurso Especial no 778.217 - BA).

Apesar do Termo de Ajustamento de Conduta ser um mecanismo extrajudicial na solução de conflitos, principalmente o ambiental, este procedimento, se comparado a ações judiciais, ainda é pouco utilizado no Brasil que tem, fruto de anos de tradição, um apego ao Poder Judiciário para solução de controvérsias, mesmo ciente que este é lento, seja pelo acúmulo de várias demandas, seja pelo prazo privilegiado da Fazenda Pública, seja pela solenidade processual, e muitas vezes ineficaz pela própria morosidade das decisões e seu cumprimento.

O que se vê, na prática, é que os TACs poderiam ser mais utilizados como instrumentos alternativos as demandas judiciais e que, após firmados, entre os agentes causadores dos danos ambientais e as partes lesadas, através do órgão público intermediador, o poder público é ineficiente no seu poder de polícia administrativo e fiscalizador para supervisão quanto ao implemento das ações pactuadas nos compromissos, que muitas vezes não são cumpridos.

\section{CONSIDERAÇÕES FINAIS}

O meio ambiente há anos sofre com a degradação e poluição ambiental. O conjunto de eventos degradativos, potencializados pelos avanços tecnológicos e industrialização, são os principais fatores nas mudanças ocorridas atualmente no ecossistema global. $\mathrm{O}$ crescimento da preocupação mundial somados ao uso não sustentável do planeta e de seus recursos naturais, fez com que, em junho de 1972, fosse realizada, na cidade de Estocolmo, a primeira conferência da Organização das Nações Unidas sobre Meio Ambiente. Nesta reunião se estabeleceu princípios que expressaram um Manifesto Ambiental, uma convicção comum de proteção e preservação do meio ambiente mundial. 
Vinte anos após a realização da Conferência de Estocolmo, a cidade do Rio de Janeiro sediou a Conferência Rio-92 e posteriormente, em 2012, a Rio+20, ambas também realizadas pela ONU com o objetivo de proteger o meio ambiente das ações predatórias do homem. Elas mostraram a preocupação mundial com a questão ambiental, mas que se restam insuficientes frente a crescente industrialização e consumismo, fruto do modelo econômico capitalista.

No Brasil, a Política Nacional do Meio Ambiente (PNMA), sancionada em 1981 e posteriormente a promulgação da CRFB, em 1988, que galgou status constitucional ao meio ambiente, com a implementação do artigo 225 e seus parágrafos, foi um passo importante em prol da proteção e preservação ambiental nacional. O mesmo diploma legal ainda demonstra de forma cristalina a necessidade de se privilegiar o princípio do desenvolvimento sustentável, instituído no capítulo da Ordem Econômica, artigo 170, inciso VI, na busca de meios que permitam o desenvolvimento socioeconômico aliado à conservação da natureza, visando um menor consumismo e industrialização, com vistas ao equilíbrio ecológico.

Contudo, o homem fruto da sua ambição por lucro e poder, com o objetivo de gerar cada vez um maior crescimento econômico, utiliza de forma indiscriminada os recursos naturais, que é um bem finito, ignorando as leis ambientais vigentes.

Na busca pela recuperação do meio ambiente e reparação do dano ambiental, a jurisdicionalização tem se mostrado morosa e pouco eficaz, seja pela a pátria legis lação, seja pelo próprio procedimento oriundo das demandas, mesmo após a Emenda Constitucional n. 45 que implementou o inciso LXXVIII ao artigo $5^{\circ}$, que destaca a razoável duração do processo e celeridade processual também elencados no artigo $4^{\circ}$ do Novo Código de Processo Civil, Lei $13.105 / 15$.

Neste contexto, o TAC, instrumento extrajudicial de pacificação de conflitos neste caso, ambientais, contido na redação do artigo $5^{\circ}, \S 6^{\circ}$ da Lei da Ação Civil Pública (Lei n. 7.347/85), tem se comprovado uma alternativa viável a jurisdicionalização com o fim de se obter a satisfação da reparação ambiental. Consagra a norma que, uma vez este não cumprido terá a eficácia de verdadeiro título executivo extrajudicial, tornando mais rápida a sua efetivação, quando necessária a via judicial. 
Dentre os órgãos públicos legitimados para firmar o TAC, previstos na Lei $n$. 7.347/85, o Ministério Público é o mais atuante, porém, muitas vezes este esbarra na falta de fiscalização do cumprimento dos mesmos por parte do poder público local, que, deste modo, faz com que estes não produzam a efetividade deles esperada. Assim, enquanto o poder público carecer de iniciativas rigorosas que viabilizem e fiscalizem a preservação e proteção ambiental, mecanismos alternativos de pacificação de conflitos, como os TACs, serão instrumentos inefetivos em prol da proteção e preservação do meio ambiente.

\section{REFERÊNCIAS}

ARRUDA, Mônica Penna Sattamini de. Termo de Ajustamento de Conduta e Desregulação Ambiental. XI Encontro

ANPUR. BRASIL. Lei 7.347 de 24 de julho de 1985. Disponível em: <http://www.planalto.gov.br/ccivil_03/leis/17347orig.htm>. Acesso em 23 fev. 2016. . Ministério de Meio Ambiente. Declaração da Conferência de ONU no Ambiente Humano. Disponível em: <www.mma.gov.br/estruturas/agenda21/_arquivos/estocolmo.doc>. Acesso em: 11 abr. 2016.

Constituição da República Federativa do Brasil de 1988. promulgada em 5 de

outubro

de $\quad 1988 . \quad$ Disponível

em:

http://www.planalto.gov.br/ccivil_03/constituicao/ConstituicaoCompilado.htm». Acesso em: 11 abr. 2016.

Lei 13.105, de 16 de março de 2015. Disponível em: $<$ http://www.planalto.gov.br/ccivil_03/_ato2015-2018/2015/lei/113105.htm>. Acesso em: 11 abr. 2016.

- Lei $\mathrm{n}^{\mathrm{o}}$ 13.140, de 26 de julho de 2015. Disponível em: < http://www.planalto.gov.br/ccivil_03/_Ato2015-2018/2015/Lei/L13140.htm> Acesso em: 17 out de 2015 .

_. Lei 5.689 de 11 de janeiro de 1973. Disponível em: $<$ http://www.planalto.gov.br/ccivil_03/leis/15869compilada.htm> Acesso em: 10 maio de 2015.

. Emenda Constitucional n. 45, de 30 de dezembro de 2004. Disponível em: $<$ http://www.planalto.gov.br/ccivil_03/Constituicao/Emendas/Emc/emc45.htm $>$ Acesso em: 10 abr de 2016. 
Conselho Nacional de Justiça. Resolução n. 12529 de novembro de 2010.

Disponível em: $<$ http://www.cnj.jus.br/busca-atos-adm?documento=2579> Acesso em: 10 abr de 2016.

BREDARIOL, C.S. 2001. Conflito ambiental e negociação: para uma política local de meio ambiente.Tese de doutorado, Universidade Federal do Rio de Janeiro. 2001. Disponível em: <http://www.ppe.ufrj.br/ppe/production/tesis/dbredariocs.pdf>. Acesso em: 21 fev. 2015.

Canadian Round Tables; Building Consensus for a Sustainable Future; Round Tables on the Environment and Economy in Canada; 1993; Ottawa.

BUENO; Cassio Scarpella. Curso Sistematizado de Direito Processual Civil. São Paulo. Ed. Saraiva. V. 2. 2007.

. As Class Actions Norte-Americanas e as ações Coletivas Brasileiras: Pontos para uma reflexão conjuntal Disponível em: http://www.scarpinellabueno.com.br/Textos/Class\%20action\%20e\%20direito\%20brasileiro.p df> Acesso em: 27 out de 2015.

ESTADO DO RIO DE JANEIRO. Lei n. 3.467, de 14 de setembro de 2000. Disponível em: < http://alerjln1.alerj.rj.gov.br/CONTLEI.NSF/bff0b82192929c2303256bc30052cb1c/f6e323ae 55f376bf03256960006a0dde?OpenDocument> Acesso em: 27 marut de 2016

LOBÃO, Ronaldo; MARANHÃO, Tatiana; MILANO, Yanne. É possível inovar no Direito? As condições de possibilidade de um Termo de Acordo Socioambiental. Congresso Internacional Interdisciplinar em Sociais e Humanidades. Niterói. Rio de Janeiro. 2012. Disponível em: <http://www.aninter.com.br/ANAIS\%20I\%20CONITER/GT14\%20Conflitos\%20territoriais $\% 20$ e $\%$ 20socioambientais/14\%20\%C9\%20POSS\%CDVEL\%20INOVAR\%20NO\%20DIREI TO\%20AS\%20CONDI\%C7\%D5ES\%20DE\%20POSSIBILIDADE\%20DE\%20UM\%20TER MO\%20DE\%20ACORDO\%20SOCIOAMBIENTAL-\%20RESUMO\%20ESTENDIDO.pdf $>$. Acesso em: 24 fev. 2015.

NEVES; Daniel Amorim Assumpção. Manual de Direito Processual Civil. São Paulo. Ed. Gen. 5 edição. 2013.

. Novo CPC Código de Processo Civil. Inovações. Alterações. Supressões. São Paulo. Ed Gen/Método. 2015.

MEDINA, JoseMiguel Garcia. Quadro Comparativo entre o CPC/1973 e o CPC/2015.

MILARÉ; Édis. Direito do Ambiente. 8. ed. São Paulo: Revistas dos Tribunais , 2013.

PINHO, Humberto Dalla Bernadina de. Descendando o novo CPC. A mediação Judicial no 
Novo CPC. Porto Alegre: Livraria do Advogado. 2015.

ORGANIZAÇÃO DAS NAÇÕES UNIDAS. Declaração do Rio sobre Meio Ambiente e Desenvolvimento. Disponível em: <http:/www.onu.org.br/rio20/img/2012/01/rio92.pdf>. Acesso em: 11 abr. 2016.

. Conferência das Nações Unidas sobre desenvolvimento sustentável. . Disponível em: <http://www.onu.org.br/rio20/documentos/>. Acesso em: 11 abr. 2016.

. Disponível em: <http://www.onu.org.br/rio20/img/2012/01/estocolmo1972.pdf >. Acesso em: 05 jun. 2015.

. Disponível em: <http//www.onu.org.br/rio20/img/2012/01/rio92.pdf $>$. Acesso em: 6 Jun. 2015.

. Disponível em: <http://www.onu.org.br/a-onu-em-acao/a-onu-e-o-meio-ambiente/>. Acesso em: 17 fev. 20146

. Disponível em: <http://www.onu.org.br/a-onu-em-acao/a-onu-e-o-meio-ambiente/>. Acesso em: 17 fev. 2016.

SANTOS, Jerônimo Jesus dos. Termo de Ajustamento de Conduta. Rio de Janeiro. Editora e Livraria Jurídica do Rio de Janeiro. 2007.

SCHMIDT; L. Análise Crítica do Termo de Ajustamento de Conduta no Direito Ambiental Brasileiro. 2002. 150 f. Dissertação (Mestrado em Direito). Universidade Federal de Santa Catarina. Florianópolis. Santa Catarina. 2002.

SIMÕES; Alexandre Gazetta. A transindividualidade do direito fundamental a um meio ambiente ecologicamente 2013. Disponível em: $<$ http:/jus.com.br/artigos/24451/a-transindividualidade-do-direito-fundamental-a-um-meioambiente-ecologicamente-equilibrado>. Acesso em: 5 jun. 2013.

SILVA; José Afonso da. Curso de Direito Constitucional Positivo. 9. ed. São Paulo: Malheiros, 1993.

SILVA; Thomas de Carvalho. Considerações Gerais acerca do Direito Ambiental. Disponível em: <http://www.egov.ufsc.br/portal/sites/default/files/consid_gerais_direito_ambiental.pdf $>$ Acesso em: 5 fev. 2016.

SIRVINSKAS; Luís Paulo. Tutela Constitucional do Meio Ambiente. 2. ed. Rio de Janeiro: Saraiva, 2010.

SUPERIOR TRIBUNAL DE JUSTIÇA. Recurso Especial n 1.540.360 - RS. Disponível em: $<$ https://ww2.stj.jus.br/processo/revista/documento/mediado/?componente=ATC\&sequencia $>$ 
Acesso em: 5 fev. 2016.

THEODORO JÚNIOR, Humberto; NUNES, Dierle; BAHIA, Alexandre Melo Franco; PEDRON, Flávio Quinaud. Novo CPC. Fundamentos e Sistematização. Rio de Janeiro: Gen/Forense. 2015.

VIÉGAS; R. N. As resoluções de conflito ambiental na esfera pública brasileira: uma análise crítica. REVISTA CONFLUÊNCIAS . Universidade Federal Fluminense. Niterói. Rio de Janeiro. $\quad$ p. $23 \quad-\quad 2007 . \quad 50.2007$ Disponível $<$ http://www.confluencias.uff.br/index.php/confluencias/article/view/104>. Acesso em: 24 fev. 2015. 